\title{
Survey on: Privacy Preserving and Trivial Security Method for Smart Grid Client-Side Networks using NTRU
}

\author{
Nitesh Wamanrao Dangare ${ }^{1}$, Sandip D. Satav ${ }^{2}$ \\ ${ }^{1}$ ME Computer Engineering, Jayawantrao Sawant College of Engineering, Hadapsar Pune-28, Savitribai Phule Pune University, Pune, India \\ ${ }^{2}$ Assistant Professor, Information Technology, Jayawantrao Sawant College of Engineering, Hadapsar Pune-28, Savitribai Phule Pune \\ University, Pune, India
}

\begin{abstract}
Data security and clients' protection in keen network are critical concerns. Existing security and protection protecting plans consider that the utilization reports for power utilization total and charging reasons for existing are sent irregular. These intermittent messages expand the calculation what's more, correspondence weight on limited abilities smart meters. In this paper, we propose a lightweight security and protection saving plan that depends on anticipating the power interest for a group of houses in the same local location; it limits the bunch's association with power utility just when the bunch needs to conform its aggregate interest. The plan effectively fulfills the security and protection necessities in client side systems, i.e., correspondence in the middle of clients and force utility. In the meantime, it altogether lessens the correspondence furthermore, calculation overhead. Besides, the proposed plan uses NTRU cryptosystem to further lessen the calculation multifaceted nature.
\end{abstract}

Keywords: Building area networks (BANs), home area networks (HANs), lattice-based scheme NTRU.

\section{Introduction}

Savvy GRID is the fuse between customary power framework and correspondence and data innovations, where different systems administration strategies are used to trade data about network's conditions and clients' requests between distinctive gatherings to enhance power era what's more, conveyance and diminish power misfortunes. Through various systems administration advances, three principle systems are sent in shrewd framework: the first sort is the home range system (HAN), which is in charge of registering power utilization for clients. To perform its errand, HAN comprises of a smart meter that unites with house's keen apparatuses in request to total their utilization readings.

Brilliant GRID is the joining between customary power matrix and correspondence and data advancements, where different systems administration methods are used to trade data about matrix's conditions and clients' requests between distinctive gatherings to enhance power era what's more, spreading and reduce power misfortunes. Through assorted systems administration advancements, three fundamental systems are conveyed in keen lattice: the first sort is the home zone system (HAN), which is in charge of registering power utilization for clients. To perform its assignment, HAN comprises of a shrewd (smart) meter that interfaces with house's savvy apparatuses in request to total their utilization readings.

\section{Related Work}

1) In this paper the author studied,in this paper, we propose another cross section based ring mark plan which security can be decreased to an understood mark plan, NTRUSign. This new ring mark incredibly diminishes the key space and the mark length contrasting and the current cross section based ring mark plans. Our plan is suitable for portable lightweight gadgets, for example, shrewd cards, phone, and RFID tokens.

2) In the paper [2],the author demonstrated Cyber-Physical System Security for the Electric Power Grid, The advancement of a reliable shrewd lattice requires a more profound comprehension of potential effects coming about from fruitful digital assaults. Assessing possible assault effect requires an assessment of the matrix's reliance on its digital framework and its capacity to endure potential disappointments. A further investigation of the cyber-physical connections inside the brilliant matrix and a particular audit of conceivable assault vectors are important to decide the sufficiency of cyber security endeavors. This paper highlights the noteworthiness of digital framework security in conjunction with force application security to anticipate, alleviate, and endure digital assaults. A layered methodology is acquainted with assessing danger taking into account the security of both the physical force applications and the supporting digital base. An order is introduced to highlight conditions between the cyberphysical controls required to bolster the brilliant matrix and the correspondence and calculations that must be defended from digital assault. The paper then introduces flow research endeavors went for improving the brilliant lattice's application and foundation security. At last, current difficulties are distinguished to encourage future exploration endive.

3) The author demonstrated Increasing Smart Meter Privacy through Energy Harvesting and Storage Devices Brilliant meters are key components for the operation of brilliant frameworks. By giving close real time data on the vitality utilization of individual clients, brilliant meters increment the effectiveness in era, dispersion and capacity of vitality in a brilliant matrix. The capacity of 


\section{International Journal of Science and Research (IJSR) \\ ISSN (Online): 2319-7064}

Index Copernicus Value (2013): 6.14 | Impact Factor (2014): 5.611

the utility supplier to track clients' vitality utilization definitely prompts essential dangers to protection. In this paper, protection in a shrewd metering framework is concentrated on from a data theoretic point of view in the locality of strength reaping and stockpiling units. It is demonstrated that vitality diversifying so as to reap gives expanded protection the vitality source, while a capacity gadget can be utilized to increment both the vitality productivity and the security of the client. For given info burden and vitality gathering rates, it is demonstrated that there exists an exchange off between the data spillage rate, which is utilized to quantify the protection of the client, and the squandered vitality rate, which is a measure of the vitality proficiency. The effect of the vitality collecting rate and the measure of the stockpiling gadget on this exchange off is likewise contemplated.

4) The author studied [4], Smart Grid Security and Privacy: Challenges, Literature Survey and Issues Security in shrewd lattice is testing. Brilliant Grid is perceived as two way correspondence innovation. There are various correspondences, canny, checking and electrical components utilized in force framework that makes it keen. These components consistently produces cum genuine auspicious talks the basic data like observing information, client vitality utilization, network status, request reaction and so on among the savvy matrix gadgets. In this way, security assaults on such a framework debilitate the security of brilliant network, results in serious outcomes. In this way, this paper quickly talks about the critical security and security difficulties, issues and some feasible answers for ensuring the savvy lattice.

5) In this paper [5] the author studied, while expanding the productivity in era, distribution and capacity of vitality in a shrewd network, savvy meters additionally permit the utility supplier to screen the vitality utilization conduct of the clients, prompting critical dangers to security. In this paper, protection in a savvy metering framework is examined from a data theoretic point of view in the vicinity of vitality gathering and stockpiling units. It is demonstrated that vitality diversifying so as to collect gives expanded protection the vitality source, while the capacity gadget can be utilized to increment both the vitality productivity and the security of the client. For given data burden and vitality gathering rates, it is demonstrated that there exists an exchange off between the data spillage rate, which is utilized to quantify the protection of the client, and the squandered vitality rate, which is a measure of the vitality proficiency. The effect of the vitality gathering rate and the measure of the stockpiling gadget on this exchange off is additionally concentrated on.

Table 1: Comparative Study

\begin{tabular}{|c|c|c|c|c|c|}
\hline $\begin{array}{l}\text { Sr. } \\
\text { No. }\end{array}$ & Paper & Technique & Advantages & Disadvantages & Result \\
\hline 1. & $\begin{array}{l}\text { Cyber-physical } \\
\text { system } \\
\text { security for the } \\
\text { electric power grid }\end{array}$ & \begin{tabular}{|c|} 
It presents current research \\
efforts aimed at enhancing the \\
smart grid's application and \\
infrastructure security
\end{tabular} & \begin{tabular}{|c|} 
It provides an smart \\
grid operation, \\
associated cyber \\
infrastructure and \\
power system \\
controls \\
\end{tabular} & \begin{tabular}{|c|} 
Security mechanisms \\
may still remain \\
vulnerable to \\
additional attack \\
vectors
\end{tabular} & $\begin{array}{c}\text { The significance of cyber } \\
\text { infrastructure security in } \\
\text { conjunction with power } \\
\text { application security to } \\
\text { prevent, mitigate, and tolerate } \\
\text { cyber attacks } \\
\end{array}$ \\
\hline 2. & $\begin{array}{l}\text { A distortion-based } \\
\text { approach to } \\
\text { privacy preserving } \\
\text { metering in smart } \\
\text { grids }\end{array}$ & $\begin{array}{l}\text { An efficient distortion-based } \\
\text { privacy-preserving metering } \\
\text { scheme that protects an } \\
\text { individual customer's privacy }\end{array}$ & $\begin{array}{c}\text { Proposed scheme is } \\
\text { robust against } \\
\text { known attacks }\end{array}$ & $\begin{array}{l}\text { It does not demand } \\
\text { new facilities on } \\
\text { existing smart grids }\end{array}$ & $\begin{array}{l}\text { A random noise is purposely } \\
\text { introduced to distort } \\
\text { customers' power } \\
\text { consumption data at the smart } \\
\text { meter so that data recovery } \\
\text { becomes infeasible } \\
\end{array}$ \\
\hline 3. & $\begin{array}{c}\text { Securing smart } \\
\text { grid cyber attacks, } \\
\text { countermeasures, } \\
\text { and challenges }\end{array}$ & $\begin{array}{c}\text { It describe smart grid goals and } \\
\text { tactics, and present a three } \\
\text { layer smart grid network } \\
\text { architecture }\end{array}$ & \begin{tabular}{|c|} 
It detects and \\
responds to \\
weaknesses or \\
failures by \\
instructing the \\
control devices to \\
take proper actions
\end{tabular} & $\begin{array}{c}\text { It requires more efforts } \\
\text { to trigger }\end{array}$ & $\begin{array}{c}\text { Here elaborate on smart grid } \\
\text { cyber security issues. }\end{array}$ \\
\hline 4. & $\begin{array}{l}\text { Privacy-preserving } \\
\text { advancepower } \\
\text { reservation }\end{array}$ & \begin{tabular}{|} 
The feasibility of designing \\
privacy-preserving smart \\
meters using low-cost \\
microcontrollers and provide a \\
general methodology for \\
estimating design costs.
\end{tabular} & $\begin{array}{l}\text { It is possible to } \\
\text { reduce the RAM } \\
\text { requirements by } \\
\text { about } 50 \%\end{array}$ & $\begin{array}{l}\text { Performance is not } \\
\text { good. }\end{array}$ & $\begin{array}{c}\text { To provide smart meter } \\
\text { designers with a general } \\
\text { methodology for selecting an } \\
\text { appropriate balance between } \\
\text { platform performance }\end{array}$ \\
\hline
\end{tabular}

\section{Architectural View}




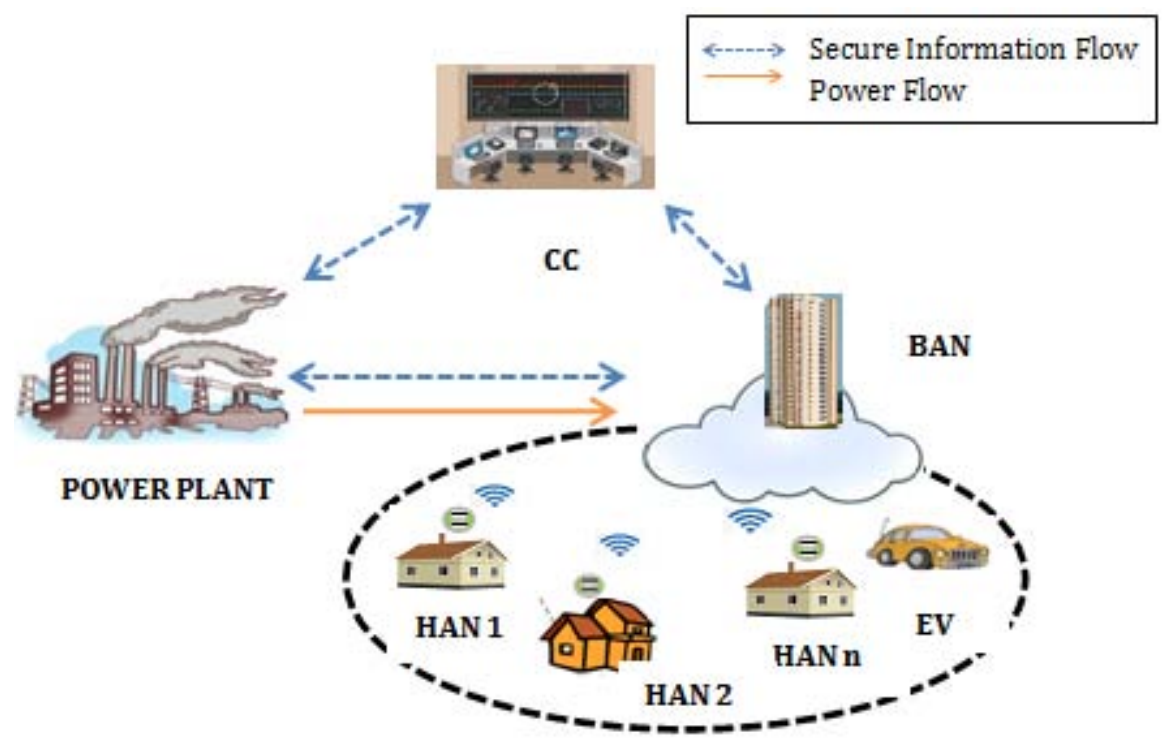

Figure 1: System Architecture

\section{Conclusion}

Major attentiveness toward client side systems in keen lattice. In spite of the current arrangements, they have proposed a lightweight security and protection saving plan based on foreseeing the normal power interest for a group of HANs. The proposed plan ensures the power clients' security even though guaranteeing the secrecy what's more, trustworthiness of the traded power utilization messages. It likewise limits the association with the supplier just when the aggregate bunch's interest should be balanced. Security investigation and reproduction results show that the proposed plan fulfills security and protection prerequisites for householders; in the meantime, it ensures light correspondence also, calculation trouble. Later on work, they point to concentrate on the effect of vindictive BANs on the execution of client side systems.

\section{References}

[1] AsmaaAbdallah and XueminShen, Fellow, IEEE2. Lightweight Security and Privacy Preserving Scheme for Smart Grid Customer-Side Networks,

[2] C. Wang and H. Wang, "A new ring signature scheme from NTRU lattice," in Proc. ICCIS, Chongqing, China, 2012, pp. 353-356.

[3] S. Sridhar, A. Hahn, and M. Govindarasu, "Cyberphysical system security for the electric power grid," Proc. IEEE, vol. 100, no. 1, pp. 210-224, Jan. 2012.

[4] O. Tan, D. Gunduz, and H. Poor, "Increasing smart meter privacy through energy harvesting and storage devices," IEEE J. Sel. Areas Commun., vol. 31, no. 7, pp. 13311341, Jul. 2013.

[5] L. Sankar, S. Rajagopalan, S. Mohajer, and H. Poor, "Smart meter privacy: A theoretical framework," IEEE Trans. Smart Grid, vol. 4, no. 2, pp. 837-846, Jun. 2013.

[6]X. Li et al., "Securing smart grid cyber attacks, countermeasures, and challenges," IEEE Commun. Mag., vol. 50, no. 8, pp. 38-45, Aug. 2012.

[7] T. Chim, S. Yiu, L. Hui, and V. Li, "Privacy-preserving advance power reservation," IEEE Commun. Mag., vol. 50, no. 8, pp. 18-23, Aug. 2012.

\section{Author Profile}

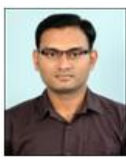

Mr. Nitesh W. Dangare, is currently pursuing M.E (Computer) from Department of Computer Engineering, Jayawantrao Sawant College of Engineering, Pune, India. Savitribai Phule Pune University, Pune, Maharashtra, India-411007. He received his B.E (Computer) Degree from Jayawantrao Sawant College of Engineering, Pune, India. Savitribai Phule Pune University, Pune, Maharashtra, India-411007 in 2013. His area of interest is Network security, and Smart Grid.

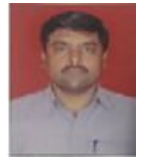

Asst Prof. S.D.Satav, received his M.E (CSE/IT) degree from the Department of Computer Engineering, Vishwakarma Institute of Technology, Savitribai Phule Pune University, Pune, Maharashtra, India 411007 in 2004. He is currently working as Asst. Professor with Department of Information Technology, Jayawantrao Sawant College of Engineering, Savitribai Phule Pune University, Pune, Maharashtra, India-411007. He received his B.E (E\&TC) Degree from SVPM's College of Engineering, Pune, India. Savitribai Phule Pune University, Pune, Maharashtra, India411007 in 2002. His research interests include Image Processing, and Networking. 